\title{
Anterior Cruciate Ligament Reconstruction
}

\section{Quadriceps Versus Patellar Autograft}

\author{
Hyuk Soo Han MD, Sang Cheol Seong MD, PhD, \\ Sahnghoon Lee MD, Myung Chul Lee MD, PhD
}

Received: 5 April 2007 / Accepted: 11 September 2007

(C) The Association of Bone and Joint Surgeons 2008

\begin{abstract}
The bone-patellar tendon-bone has been widely used and considered a good graft source. The quadriceps tendon was introduced as a substitute graft source for bonepatellar tendon-bone. We compared the clinical outcomes of anterior cruciate ligament reconstructions using central quadriceps tendon-patellar bone and bone-patellar tendonbone autografts. We selected 72 patients who underwent unilateral anterior cruciate ligament reconstruction using bone-patellar tendon-bone between 1994 and 2001 and matched for age and gender with 72 patients who underwent anterior cruciate ligament reconstruction using quadriceps tendon-patellar bone. All patients were followed up for more than 2 years. We assessed anterior laxity, knee function using the Lysholm and International Knee Documentation Committee scores, and quadriceps strength, the means of which were similar in the two groups. More patients (28 or 39\%) in the bone-patellar tendon-bone group reported anterior knee pain than in the quadriceps tendon-patellar bone group (six patients or 8.3\%). Anterior cruciate ligament reconstruction using the central quadriceps tendon-patellar bone graft showed clinical outcomes comparable to those of anterior cruciate ligament reconstruction using the patellar tendon graft, with anterior knee pain being less frequent in the former.
\end{abstract}

One of the authors (MCL) has received funding from Seoul National University Hospital (22-2006-002).

Each author certifies that his institution has approved the human protocol for this investigation, that all investigations were conducted in conformity with ethical principles of research, and that informed consent was obtained.

H. S. Han, S. C. Seong, S. Lee, M. C. Lee ( $\square)$

Department of Orthopaedic Surgery, Seoul National University,

College of Medicine, 110-744 Seoul, South Korea

e-mail: leemc@snu.ac.kr
Our data suggest the quadriceps tendon can be a good alternative graft choice.

Level of Evidence: Level III Therapeutic study. See the Guidelines for Authors for a complete description of levels of evidence.

\section{Introduction}

The outcomes of the bone-patellar tendon-bone (BPTB) autograft for anterior cruciate ligament (ACL) reconstruction have been reported and BPTB has been considered a good graft source [3, 40]. The popularity of BPTB probably is related to the following advantages: initial quality of fixation, high initial strength and stiffness, potential for bone-to-bone healing, better stability with time, improved rate of return to activities such as strenuous sports, and overall increased activity level $[3,8,38]$. The hamstring tendon autograft was reintroduced with the development of improved fixation techniques [7, 11, 12, 34]. However, every autograft option has several potential limitations of donor site morbidities, graft strengths and stiffness, fixation problems, host tissue incorporation, and others [16, 19-21, 24, 27, 29, 32, 35, 36, 38, 42].

In 1997, we began using the quadriceps tendon-patellar bone (QTPB) autograft, as introduced by Blauth [4] and further studied by Stäubli [43], because it was believed this would minimize donor site morbidity including anterior knee pain while providing adequate mechanical strength as a graft. Several reports have suggested mechanical testing and histomorphometric measures for quadriceps tendon are comparable to those for BPTB [13, 15, 41, 44]. However, few studies have compared the clinical outcomes of the quadriceps free tendon graft and BPTB grafts [17, 33], and 
to our knowledge, none compares clinical outcomes with the QTPB graft.

We asked whether the outcomes differed with QTPB and BPTB grafts used for ACL reconstruction regarding postoperative motion and anteroposterior knee stability, activity and functional scores, quadriceps muscle strength and incidence of anterior knee pain, and other complications.

\section{Materials and Methods}

We designed this retrospective comparative study to identify any differences between the clinical outcomes of ACL reconstructions using QTPB or BPTB autografts. First, we assessed postoperative motion return and anteroposterior knee stability. Second, activity and functional changes were documented using questionnaires, and differences between quadriceps muscle strength recoveries for the two grafts were assessed. Finally, we determined and compared the incidences of anterior knee pain and other complications. Between May 1994 and July 2001, 430 consecutive patients with symptomatic ACL insufficiency underwent arthroscopically assisted ACL reconstructions using autologous BPTB or QTPB grafts by two surgeons (SCS, MCL). The choice of graft was based on discussions between the patient and the physician. We included only patients with unilateral ACL insufficiency and more than 2 years followup. We excluded patients with previous ligament injury of the affected knee and concomitant ligament injury of the affected knee except for a Grade I or II injury of the medial collateral ligament. Seventy-two (68 males, four females) of 97 patients who had BPTB autografts and 240 (212 males, 27 females) of 333 patients who had QTPB autografts met these criteria. We then matched 72 patients in the BPTB group for age and gender with 72 patients in the QTPB group. The amount of anterior translation and the incidence of postoperative anterior knee pain were considered key variables, and we performed power analysis with reference to the results of previous studies $[22,26]$. A power analysis suggested we needed 66 patients in each group to detect one standard deviation difference at $80 \%$ power in the key variables.

The mean followups for the BPTB group (42.1 months; range, 24-124 months) and the QTPB group (39.7 months; range, 24-90 months) were similar. We observed no differences in demographic data between the two groups (Table 1). Most injuries were sports-related. Fifty-one patients $(71 \%)$ in the BPTB group and 46 patients $(64 \%)$ in the QTPB group underwent surgery for meniscal tears during ACL reconstruction. Although we observed Grade I or II injuries of the medial collateral ligament in four patients $(5.6 \%)$ in both groups, none had surgical intervention.
Table 1. Patient demographics

\begin{tabular}{llll}
\hline Variable & BPTB group & QTPB group & p Value \\
\hline Number of patients & 72 & 72 & \\
Gender (male/female) & $68 / 4$ & $68 / 4$ & \\
Age at surgery (years) & $27.8(15-51)$ & $27.8(15-51)$ & \\
Time from injury to surgery & $23.4(0.5-120)$ & $21.4(0.5-88)$ & 0.61 \\
$\quad$ (months) & & & \\
Followup (months) $^{*}$ & $42.1(24-124)$ & $39.7(24-90)$ & 0.49 \\
\hline
\end{tabular}

${ }^{*}$ Values are expressed as means, with ranges in parentheses; $\mathrm{BPTB}=$ bone-patellar tendon-bone; $\quad \mathrm{QTPB}=$ quadriceps tendonpatellar bone.

We harvested the BPTB through a 5-cm vertical incision centered on the patellar tendon. A 10-mm-wide middlethird patellar tendon graft was obtained with a $25-\mathrm{mm}$-long trapezoidal patellar bone block and a 25 -mm-long tibial block. The bone defect was not grafted, and the patellar tendon defect was approximated using absorbable sutures. Both ends were fashioned to pass through a $10-\mathrm{mm}$ diameter gauge. We drilled two holes in each bone block to be used for lead threads. After a graft had been harvested, we created a $10-\mathrm{mm}$-diameter tibial tunnel so the intraarticular opening of the tunnel could be placed in the center of the ACL attachment using an ACL endoscopic guide system (Smith and Nephew, Inc, Andover, MA). A femoral tunnel $10 \mathrm{~mm}$ in diameter was drilled through the tibial tunnel in the 10:30 to 11 o'clock position for the right knee (the posterior cortex of this tunnel should be approximately $2 \mathrm{~mm}$ thick). Notchplasty was performed for observation of the femoral tunnel and to prevent graft impingement if needed. After the graft had been passed through the tunnels, a metal interference screw (Linvatec, Largo, FL), which was $7 \times 25 \mathrm{~mm}$ on most occasions, was used to fix the bone block on the femoral side and the knee then was cycled 15 to 20 times through a full range of motion with the graft under tension. The bone block on the tibial side was fixed with another metal interference screw.

We harvested the QTPB through a 4-cm midline incision centered over the proximal border of the patella. A 10-mm-wide, 20- to 25-mm-long, 7-mm-thick trapezoidal bone block was obtained from the patellar base using an oscillating saw. We then excised a 10-mm-wide, 6- to 8-mm-thick, and 6-cm-long strip of the quadriceps tendon from the distal portion in continuity with the patellar bone block initially using a 10 -mm ParaSmillie ${ }^{\mathbb{R}}$ Graft Harvester (Linvatec) and then later finishing with Metzenbaum scissors (Fig. 1). Care was taken not to enter the suprapatellar pouch by saving part of the vastus intermedius tendon. If entry occurred, we repaired the synovial lining with an absorbable suture. Superficial layers of the cut surface of the tendon were closed transversely with absorbable coapting sutures leaving a potential space over 


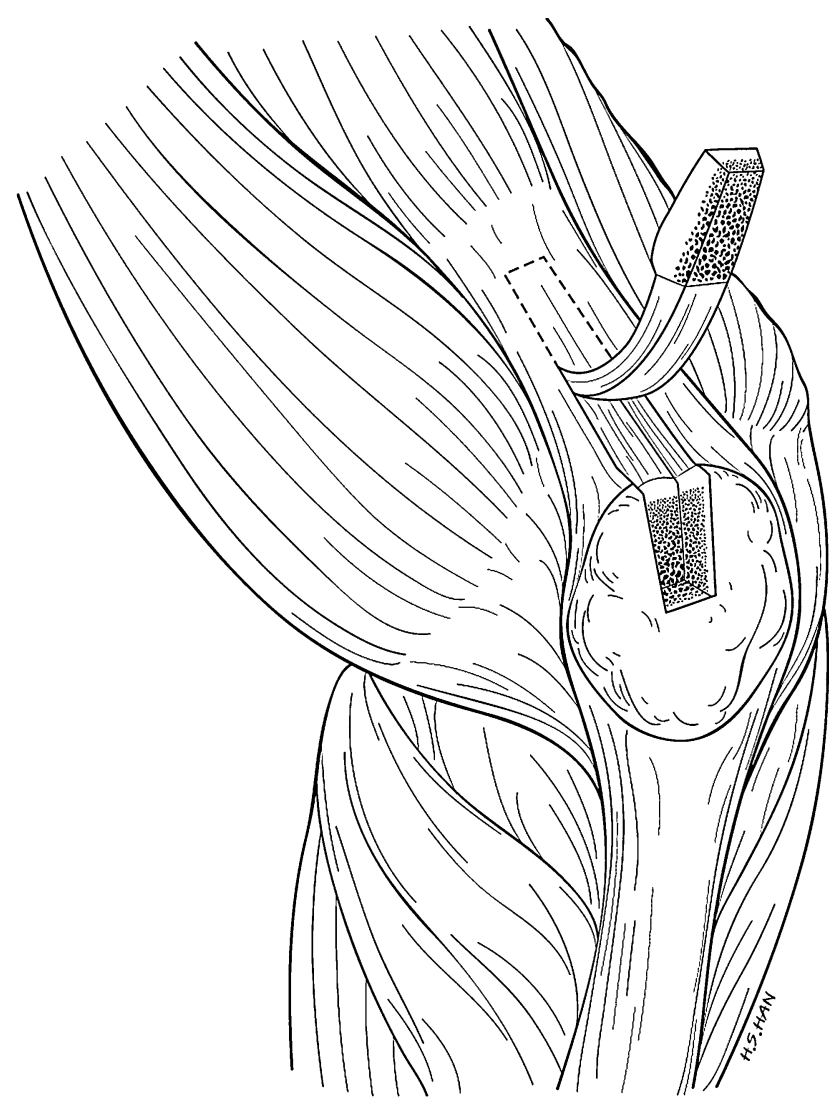

Fig. 1 A strip of the quadriceps tendon was excised from the distal portion in continuity with the patellar bone. A part of the vastus intermedius tendon was saved.

the defect. The bone defect was not grafted or closed. The bone block from the patellar base was perforated transversely with drill holes, and two absorbable sutures were passed. We secured the tendinous portion of the graft with two Number 5 Ethibond $^{\text {TM }}$ sutures (Ethicon, Inc, Somerville, NJ) using Krackow-type stitches with an extension of approximately $30 \mathrm{~mm}$ (Fig. 2). Femoral and tibial tunnels were positioned in the same manner as described for the

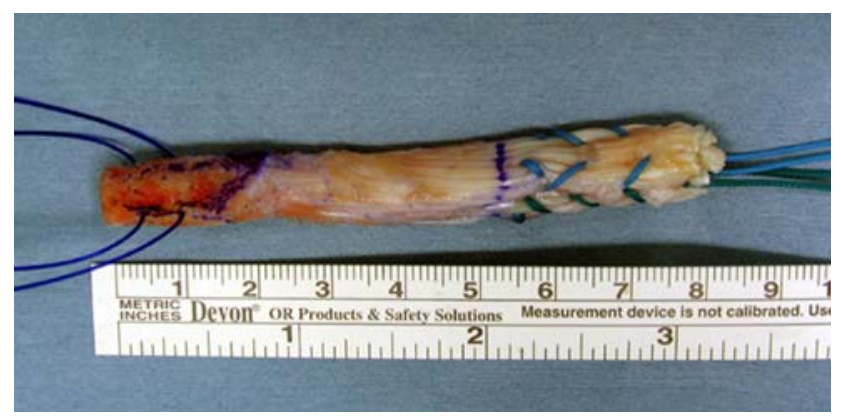

Fig. 2 The patellar bone block was perforated transversely with a drill, and two absorbable sutures were passed. The graft tendinous portion was secured with two nonabsorbable sutures using Krackowtype stitches.
BPTB graft. During the QTPB procedure, we fixed the tendinous portion on the tibial side with a bioabsorbable screw (Bioscrew ${ }^{\circledR}$; Linvatec), which measured $8 \times 25 \mathrm{~mm}$ or $9 \times 25 \mathrm{~mm}$, for a tight fit, and this was augmented by tying sutures over the bicortical screw distally with the knee extended.

For all patients, continuous passive motion was started from $45^{\circ}$ knee flexion within 3 days and continued for 1 to 2 days while patients were hospitalized. Full extension was achieved during the first postoperative week, and full flexion was achieved by 6 weeks. Kinetic exercise and weightbearing were progressed as tolerated, and a motioncontrolled brace set at $0^{\circ}$ to $90^{\circ}$ was worn for 3 weeks and then was set at $0^{\circ}$ to full flexion for an additional 4 weeks postoperatively. Full activity such as strenuous sport was permitted 6 months postoperatively after confirming recovery of quadriceps strength. We used no custom orthoses.

We (SCS, MCL) evaluated all patients at 6 weeks and then at approximately 3-month intervals until 12 months (3, 6, 9, and 12 months), after which they were seen at 12month intervals $(24,36$, and 48 months). We assessed the range of motion by goniometry and anterior laxity grades, which involved the Lachman test, the anterior drawer test, and the pivot shift test. We measured anterior translation using a KT- $1000^{\mathrm{TM}}$ arthrometer (MEDmetric ${ }^{\circledR}$ Corp, San Diego, CA). Injured and contralateral normal knees were measured with a maximum manual anterior force applied to the proximal tibia at $20^{\circ}$ knee flexion. The side-to-side difference in anterior laxity (injured minus normal) was used as a representative indicator of restored knee stability. We defined graft failure as patients showing Grade 2 or 3 $(>5 \mathrm{~mm}$ ) anterior laxity and complaining of knee instability. We measured peak extension torque using a Cybex II isokinetic testing device (Cybex, Ronkonkoma, NY) at $60^{\circ}$ and $180^{\circ}$ per second with the patient's informed consent. We presumed the side-to-side ratio at peak torque represented thigh muscle strength. Reviews involved the modified Lysholm Knee Scoring Scale [45] and documentation of the International Knee Documentation Committee (IKDC) [2] for levels of activities and subjective satisfaction. We evaluated anterior knee pain subjectively using the Shelbourne and Trumper questionnaire addressing symptoms during sports or daily life activities and kneeling pain [39].

Kolmogorov-Smirnov tests revealed ratio scale data had a consistently normal distribution, and thus the paired $t$ test was used for comparing the data from the two groups. We used the chi square test to analyze nominal and ordinal scale data (grades of ligament stability, IKDC levels, and the existence of anterior knee pain). Significance was set at $\mathrm{p}<0.05$. Statistical analysis was done using SPSS 11.5 (SPSS Inc, Chicago, IL). 


\section{Results}

Of the 144 patients in this study, one patient $(1.4 \%)$ in the BPTB group and two patients $(2.8 \%)$ in the QTPB group underwent revision ACL reconstruction because of graft failure. The patient in the BPTB group experienced indirect trauma 64 months postoperatively. Of the two patients with graft failure in the QTPB group, one had a traumatic rupture, which occurred while playing soccer 45 months after surgery, and the other graft failed from an unknown etiology (without a history of distinct injury), and the patient then underwent reoperation 30 months after surgery.

Almost all patients achieved full extension and flexion. At final followup, an extension deficit less than $5^{\circ}$ was observed in two patients in the BPTB group and in three patients in the QTPB group, and one patient in the QTPB group had an extension deficit of $10^{\circ}$. We observed a flexion deficit of $10^{\circ}$ in two patients in both groups, and one patient in the QTPB group had a flexion deficit of $40^{\circ}$.

Table 2. KT- $1000^{\mathrm{TM}}$ arthrometric data at followup

\begin{tabular}{lcc}
\hline $\begin{array}{l}\text { Side-to-side difference } \\
\text { in anterior laxity }(\mathrm{mm})\end{array}$ & BPTB group & QTPB group \\
\hline$<3$ & $52(72.2 \%)$ & $48(66.6 \%)$ \\
$3-5$ & $17(23.6 \%)$ & $21(29.2 \%)$ \\
$5-10$ & $3(4.2 \%)$ & $3(4.2 \%)$ \\
$>10$ & 0 & 0
\end{tabular}

BPTB = bone-patellar tendon-bone; $\mathrm{QTPB}=$ quadriceps tendonpatellar bone.

Table 3. Postoperative changes in IKDC activity [2]

\begin{tabular}{llllll}
\hline Activity & Preinjury & & & \multicolumn{2}{l}{ Final followup } \\
\cline { 2 - 3 } \cline { 5 - 6 } \cline { 5 - 6 } & $\begin{array}{l}\text { BPTB } \\
\text { group }(\%)\end{array}$ & $\begin{array}{l}\text { QTPB } \\
\text { group }(\%)\end{array}$ & & $\begin{array}{l}\text { BPTB } \\
\text { group }(\%)\end{array}$ & $\begin{array}{l}\text { QTPB } \\
\text { group (\%) }\end{array}$ \\
\hline I (strenuous) & 40 & 38 & 31 & 28 \\
II (moderate) & 53 & 57 & & 51 & 56 \\
III (light) & 7 & 5 & & 18 & 16 \\
IV (sedentary) & 0 & 0 & & 0 & 0
\end{tabular}

IKDC $=$ International Knee Documentation Committee; BPTB = bone-patellar tendon-bone; QTPB = quadriceps tendon-patellar bone.
We found no difference in extension or flexion deficit between the two groups.

Greater than $95 \%$ of patients in both groups showed a Grade 0 or 1 laxity by the anterior drawer test, the Lachman test, or the pivot shift test at final followup. At final followup, the mean side-to-side differences in anterior laxity during manual maximum testing were similar in the two groups (Table 2).

We found levels of sports activities were reduced at final followups in both groups, but with similar reductions in both groups (Table 3). Sixty-eight patients (94\%) in the BPTB group and 66 patients $(92 \%)$ in the QTPB group graded their knees as normal (Grade A) or nearly normal (Grade B) at final followup. Mean preoperative Lysholm scores in the BPTB and QTPB groups were 71.2 and 70.7, respectively, and these improved to 92.8 and 91.5 at final followup. No differences were found between the two groups.

Side-to-side ratios of peak torque at $60^{\circ}$ and $180^{\circ}$ per second were similar preoperatively and diminished at 6 months postoperatively in both groups. Corresponding quadriceps muscle strengths recovered to approximately $80 \%$ in both groups at 1 year postoperatively (Table 4). No difference was evident between the two groups.

For most activities, including sports and work, 28 patients $(39 \%)$ in the BPTB group and six patients $(8.3 \%)$ in the QTPB group reported moderate to severe symptoms. Kneeling pain was moderate to severe in 25 patients $(35 \%)$ in the BPTB group and in four patients (5.5\%) in the QTPB group. Thus, anterior knee pain was less common $(\mathrm{p}<0.05)$ in the QTPB group. In the BPTB group, one postoperative infection occurred and was treated with arthroscopic débridement and intravenous antibiotics; postoperative stiffness of the affected joint occurred and was treated with manipulation under anesthesia and physical therapy. In the QTPB group, one patient experienced a postoperative patellar fracture as result of a fall 5 months after reconstruction. This undisplaced and longitudinal fracture was treated nonoperatively and resulted in no complication or functional deficit at final followup. One patient in the QTPB group who had a $40^{\circ}$ flexion deficit was treated with manipulation under anesthesia and physical therapy.

Table 4. Side-to-side ratio of peak torque values by Cybex II isokinetic testing

\begin{tabular}{|c|c|c|c|c|c|c|}
\hline \multirow[t]{2}{*}{ Isokinetic test } & \multicolumn{2}{|l|}{6 Months } & \multicolumn{2}{|l|}{1 Year } & \multicolumn{2}{|l|}{2 Years } \\
\hline & $\begin{array}{l}\text { ВРТВ } \\
\text { group }(n=21)\end{array}$ & $\begin{array}{l}\text { QTPB } \\
\text { group }(\mathrm{n}=34)\end{array}$ & $\begin{array}{l}\text { ВРTB } \\
\text { group }(n=15)\end{array}$ & $\begin{array}{l}\text { QTPB } \\
\text { group }(\mathrm{n}=25)\end{array}$ & $\begin{array}{l}\text { BPTB } \\
\text { group }(n=9)\end{array}$ & $\begin{array}{l}\text { QTPB } \\
\text { group }(\mathrm{n}=19)\end{array}$ \\
\hline $60^{\circ} /$ second $(\%)$ & $52 \pm 22$ & $59 \pm 15$ & $74 \pm 20$ & $78 \pm 13$ & $78 \pm 26$ & $82 \pm 15$ \\
\hline $180^{\circ} /$ second $(\%)$ & $55 \pm 24$ & $62 \pm 17$ & $76 \pm 22$ & $82 \pm 11$ & $80 \pm 23$ & $89 \pm 8$ \\
\hline
\end{tabular}

Values are expressed as mean \pm standard deviation; BPTB = bone-patellar tendon-bone; QTPB = quadriceps tendon-patellar bone. 


\section{Discussion}

Bone-patellar tendon-bone autografts and hamstring tendon grafts are most commonly used for ACL reconstruction and produce successful results [3, 8, 25, 38]. However, several drawbacks remain unsolved because postoperative morbidities, such as anterior knee pain on climbing stairs, after long periods of sitting, or while kneeling, have been reported [8, 38, 42]. Moreover, quadriceps or hamstring isokinetic strength deficits $[9,36]$, postoperative range of motion restriction [17], late postoperative graft elongation and subsequent laxity [7, 34, 37], patellar tendon shortening or rupture $[28,29]$, and patellofemoral osteoarthritis [38] have been reported, and the quadriceps tendon has been found to have potential advantages as a graft in these aspects [13, 15, 41, 44].

This study has some inherent weaknesses because of its retrospective nonrandomized treatment selection and differing methods of graft fixation in the two groups. Patients were selectively enrolled. However, the matched design using in the large QTPB group resulted in patients with similar followups and other key variables. Cybex II isokinetic testing was performed only with the patient's informed consent and quadriceps muscle power was not serially evaluated in all study subjects. Therefore it is possible some missing data could influence the results. According to our power analysis, however, only 66 patients in each group were needed to detect one standard deviation difference at $80 \%$ power in the amount of anterior translation and the incidence of anterior knee pain. Therefore, we have confidence in our results.

Anterior cruciate ligament reconstruction using the quadriceps tendon was first reported by Marshall et al. [23]. in 1979. Until being reintroduced, the quadriceps tendon was scarcely used because of inferior clinical results [46] and concerns regarding postoperative quadriceps muscle weakness. In 1984, Blauth [4] attempted ACL reconstruction using QTPB grafts, and Stäubli [43] reported the quadriceps tendon has a sufficient amount of substance and mechanical properties for the graft in ACL reconstruction. Anatomically, the quadriceps tendon is longer and thicker than the patellar tendon and attaches to the patella more widely [13]. The mean cross-sectional area of the quadriceps tendon is larger than that of the patellar tendon regardless of preconditioning, and the mean ultimate tensile stress and strain of the patellar tendon are larger than those of the quadriceps tendon [44]. Therefore, the mean ultimate tensile failure loads (ultimate tensile strengths) for the two tendon types are similar. Tibial tunnel widening also has been reported as a result of ACL reconstruction using either the patellar tendon or the hamstring tendon [14]. It seems bungee and windshield effects occur in the patellar tendon graft because it has flat and thin morphologic features that cannot fill the tunnel sufficiently. Tunnel-graft mismatch has been reported to cause a synovial bathing effect and bone resorption through an inflow of synovial fluid and cytokines $[11,32]$. However, the relatively large crosssectional area of the quadriceps tendon reduces this mismatch and prevents tibial tunnel widening [41]. Moreover, the longer length of the quadriceps tendon enables it to be used for a graft for posterior cruciate ligament reconstruction [1].

Adequate postoperative anterior stability is most important for successful ACL reconstruction. Some recent reports suggest similar stability and functional recovery results after ACL reconstruction regardless of the type of graft [11,30-32]. Our data also suggest no difference in subjective satisfaction, anterior stability, or function between the BPTB and QTPB groups. At followup, Grade 2 or 3 anterior instability, which was considered a graft failure, occurred in three patients in the BPTB group and five patients in the QTPB group, but there was no difference between the two groups.

Anterior cruciate ligament reconstruction using the quadriceps tendon graft has the advantages of less donor site morbidity and anterior knee pain than occur with using a patellar tendon graft [10]. Our data suggest a lower incidence of anterior knee pain during various activities and kneeling pain with comparable ligament stability and clinical functions for quadriceps tendon grafts. Concern regarding weakness of the quadriceps muscle has caused many surgeons to hesitate about using its tendon as a graft. Yasuda et al. [46] reported the weakness of the quadriceps muscle based on results obtained using the Marshall graft type. Chen et al. [5, 6] used the central quadriceps tendon, as recommended by Fulkerson and Langeland [10], and reported less morbidity at the donor site. In a comparative study of kinetic exercises after ACL reconstruction, accelerated rehabilitation was identified as the most important factor for quadriceps strengthening [28]. We observed no difference in quadriceps strength recovery between the two groups as evaluated by peak torque ratio determined by Cybex isokinetic testing. This finding suggests quadriceps muscle weakness is not a serious problem if rehabilitation is adequate.

We found ACL reconstruction using the central QTPB graft showed clinical outcomes comparable to those of ACL using the BPTB graft, with anterior knee pain being less severe in the former. The data indicate the quadriceps tendon can be a good alternative graft choice.

Acknowledgments We thank the Medical Research Collaborating Center at Seoul National University for assistance with the statistical analyses. 


\section{References}

1. Aglietti P, Buzzi R, Lazzara D. Posterior cruciate ligament reconstruction with the quadriceps tendon in chronic injuries. Knee Surg Sports Traumatol Arthrosc. 2002;10:266-273.

2. Anderson AF. Rating scales. In: Fu F, Harner C, Vince K, eds. Knee Surgery. Baltimore MD: Williams and Wilkins; 1994:275-296.

3. Bach BR Jr, Tradonsky S, Bojchuk J, Levy ME, Bush-Joseph CA, Khan NH. Arthroscopically assisted anterior cruciate ligament reconstruction using patellar tendon autograft: five- to nine-year follow-up evaluation. Am J Sports Med. 1998;26:20-29.

4. Blauth W. [2-strip substitution-plasty of the anterior cruciate ligament with the quadriceps tendon]. Unfallheilkunde. 1984; $87: 45-51$.

5. Chen $\mathrm{CH}$, Chen WJ, Shih $\mathrm{CH}$. Arthroscopic anterior cruciate ligament reconstruction with quadriceps tendon-patellar bone autograft. J Trauma. 1999;46:678-682.

6. Chen CH, Chuang TY, Wang KC, Chen WJ, Shih CH. Arthroscopic anterior cruciate ligament reconstruction with quadriceps tendon autograft: clinical outcome in 4-7 years. Knee Surg Sports Traumatol Arthrosc. 2006;14:1077-1085.

7. Colombet P, Allard M, Bousquet V, de Lavigne C, Flurin PH, Lachaud C. Anterior cruciate ligament reconstruction using fourstrand semitendinosus and gracilis tendon grafts and metal interference screw fixation. Arthroscopy. 2002;18:232-237.

8. Corry IS, Webb JM, Clingeleffer AJ, Pinczewski LA. Arthroscopic reconstruction of the anterior cruciate ligament: a comparison of patellar tendon autograft and four-strand hamstring tendon autograft. Am J Sports Med. 1999;27:444-454.

9. Feller JA, Webster KE, Gavin B. Early post-operative morbidity following anterior cruciate ligament reconstruction: patellar tendon versus hamstring graft. Knee Surg Sports Traumatol Arthrosc. 2001;9:260-266.

10. Fulkerson JP, Langeland R. An alternative cruciate reconstruction graft: the central quadriceps tendon. Arthroscopy. 1995;11: 252-254.

11. Gobbi A, Mahajan S, Zanazzo M, Tuy B. Patellar tendon versus quadrupled bone-semitendinosus anterior cruciate ligament reconstruction: a prospective clinical investigation in athletes. Arthroscopy. 2003;19:592-601.

12. Hamner DL, Brown CH Jr, Steiner ME, Hecker AT, Hayes WC. Hamstring tendon grafts for reconstruction of the anterior cruciate ligament: biomechanical evaluation of the use of multiple strands and tensioning techniques. J Bone Joint Surg Am. 1999;81: 549-557.

13. Harris NL, Smith DA, Lamoreaux L, Purnell M. Central quadriceps tendon for anterior cruciate ligament reconstruction. Part I: Morphometric and biomechanical evaluation. Am J Sports Med. 1997;25:23-28

14. Hersekli MA, Akpinar S, Ozalay M, Ozkoc G, Cesur N, Uysal M, Pourbagher A, Tandogan RN. Tunnel enlargement after arthroscopic anterior cruciate ligament reconstruction: comparison of bone-patellar tendon-bone and hamstring autografts. Adv Ther. 2004;21:123-131.

15. Howe JG, Johnson RJ, Kaplan MJ, Fleming B, Jarvinen M. Anterior cruciate ligament reconstruction using quadriceps patellar tendon graft. Part I: Long-term followup. Am J Sports Med. 1991;19:447-457.

16. Jackson DW, Corsetti J, Simon TM. Biologic incorporation of allograft anterior cruciate ligament replacements. Clin Orthop Relat Res. 1996;324:126-133.

17. Joseph M, Fulkerson J, Nissen C, Sheehan TJ. Short-term recovery after anterior cruciate ligament reconstruction: a prospective comparison of three autografts. Orthopedics. 2006; 29:243-248.
18. Kaplan MJ, Howe JG, Fleming B, Johnson RJ, Jarvinen M. Anterior cruciate ligament reconstruction using quadriceps patellar tendon graft. Part II: A specific sport review. Am J Sports Med. 1991;19:458-462.

19. Kartus J, Magnusson L, Stener S, Brandsson S, Eriksson BI, Karlsson J. Complications following arthroscopic anterior cruciate ligament reconstruction: a 2-5-year follow-up of 604 patients with special emphasis on anterior knee pain. Knee Surg Sports Traumatol Arthrosc. 1999;7:2-8.

20. Kartus J, Movin T, Karlsson J. Donor-site morbidity and anterior knee problems after anterior cruciate ligament reconstruction using autografts. Arthroscopy. 2001;17:971-980.

21. Kartus J, Stener S, Lindahl S, Engström B, Eriksson BI, Karlsson J. Factors affecting donor-site morbidity after anterior cruciate ligament reconstruction using bone-patellar tendon-bone autografts. Knee Surg Sports Traumatol Arthrosc. 1997;5:222-228.

22. Lee S, Seong SC, Jo H, Park YK, Lee MC. Outcome of anterior cruciate ligament reconstruction using quadriceps tendon autograft. Arthroscopy. 2004;20:795-802.

23. Marshall JL, Warren RF, Wickiewicz TL, Reider B. The anterior cruciate ligament: a technique of repair and reconstruction. Clin Orthop Relat Res. 1979;143:97-106.

24. Marumoto JM, Mitsunaga MM, Richardson AB, Medoff RJ, Mayfield GW. Late patellar tendon ruptures after removal of the central third for anterior cruciate ligament reconstruction: a report of two cases. Am J Sports Med. 1996;24:698-701.

25. Marx RG, Jones EC, Angel M, Wickiewicz TL, Warren RF. Beliefs and attitudes of members of the American Academy of Orthopaedic Surgeons regarding the treatment of anterior cruciate ligament injury. Arthroscopy. 2003;19:762-770.

26. Matsumoto A, Yoshiya S, Muratsu H, Yagi M, Iwasaki Y, Kurosaka M, Kuroda R. A comparison of bone-patellar tendonbone and bone-hamstring tendon-bone autografts for anterior cruciate ligament reconstruction. Am J Sports Med. 2006;34: 213-219.

27. Mickelsen PL, Morgan SJ, Johnson WA, Ferrari JD. Patellar tendon rupture 3 years after anterior cruciate ligament reconstruction with a central one third bone-patellar tendon-bone graft. Arthroscopy. 2001;17:648-652.

28. Mikkelsen C, Werner S, Eriksson E. Closed kinetic chain alone compared to combined open and closed kinetic chain exercises for quadriceps strengthening after anterior cruciate ligament reconstruction with respect to return to sports: a prospective matched follow-up study. Knee Surg Sports Traumatol Arthrosc. 2000;8:337-342.

29. Muellner T, Kaltenbrunner W, Nikolic A, Mittlboeck M, Schabus $\mathrm{R}$, Vécsei V. Shortening of the patellar tendon after anterior cruciate ligament reconstruction. Arthroscopy. 1998;14:592-596.

30. Noyes FR, Barber-Westin SD. Revision anterior cruciate surgery with use of bone-patellar tendon-bone autogenous grafts. J Bone Joint Surg Am. 2001;83:1131-1143.

31. Noyes FR, Barber-Westin SD. Anterior cruciate ligament revision reconstruction: results using a quadriceps tendon-patellar bone autograft. Am J Sports Med. 2006;34:553-564.

32. Paessler HH, Mastrokalos DS. Anterior cruciate ligament reconstruction using semitendinosus and gracilis tendons, bone patellar tendon, or quadriceps tendon-graft with press-fit fixation without hardware: a new and innovative procedure. Orthop Clin North Am. 2003;34:49-64.

33. Pigozzi F, Di Salvo V, Parisi A, Giombini A, Fagnani F, Magini W, Franceschi F, Denaro E. Isokinetic evaluation of anterior cruciate ligament reconstruction: quadriceps tendon versus patellar tendon. J Sports Med Phys Fitness. 2004;44:288-293.

34. Pinczewski LA, Deehan DJ, Salmon LJ, Russell VJ, Clingeleffer A. A five-year comparison of patellar tendon versus four-strand 
hamstring tendon autograft for arthroscopic reconstruction of the anterior cruciate ligament. Am J Sports Med. 2002;30:523-536.

35. Rubinstein RA Jr, Shelbourne KD, VanMeter CD, McCarroll JC, Rettig AC. Isolated autogenous bone-patellar tendon-bone graft site morbidity. Am J Sports Med. 1994;22:324-327.

36. Sachs RA, Daniel DM, Stone ML, Garfein RF. Patellofemoral problems after anterior cruciate ligament reconstruction. Am J Sports Med. 1989;17:760-765.

37. Scranton PE Jr, Bagenstose JE, Lantz BA, Friedman MJ, Khalfayan EE, Auld MK. Quadruple hamstring anterior cruciate ligament reconstruction: a multicenter study. Arthroscopy. 2002;18:715-724.

38. Shelbourne KD, Gray T. Anterior cruciate ligament reconstruction with autogenous patellar tendon graft followed by accelerated rehabilitation: a two- to nine-year followup. Am J Sports Med. 1997;25:786-795.

39. Shelbourne KD, Trumper RV. Preventing anterior knee pain after anterior cruciate ligament reconstruction. Am J Sports Med. 1997;25:41-47.

40. Shelbourne KD, Urch SE. Primary anterior cruciate ligament reconstruction using the contralateral autogenous patellar tendon. Am J Sports Med. 2000;28:651-658.
41. Shino K, Oakes BW, Horibe S, Nakata K, Nakamura N. Collagen fibril populations in human anterior cruciate ligament allografts: electron microscopic analysis. Am J Sports Med. 1995;23:203208; discussion 209.

42. Spicer DD, Blagg SE, Unwin AJ, Allum RL. Anterior knee symptoms after four-strand hamstring tendon anterior cruciate ligament reconstruction. Knee Surg Sports Traumatol Arthrosc. 2000;8:286-289.

43. Stäubli H. Arthroscopically assisted ACL reconstruction using autologous quadriceps tendon. In: Jacob RP, Stäubli $\mathrm{H}$, eds. The Knee and the Cruciate Ligaments. Berlin, Germany: SpringerVerlag; 1997:443-452.

44. Stäubli HU, Schatzmann L, Brunner P, Rincon L, Nolte LP. Mechanical tensile properties of the quadriceps tendon and patellar ligament in young adults. Am J Sports Med. 1999;27: 27-34.

45. Tegner Y, Lysholm J. Rating systems in the evaluation of knee ligament injuries. Clin Orthop Relat Res. 1985;198:43-49.

46. Yasuda K, Ohkoshi Y, Tanabe Y, Kaneda K. Quantitative evaluation of knee instability and muscle strength after anterior cruciate ligament reconstruction using patellar and quadriceps tendon. Am J Sports Med. 1992;20:471-475. 